\title{
Cholinergic Enhancing and Antioxidant Effect of Vigna subterranea (L.) Verdc. (Fabaceae) Landrace Aqueous Extract on Scopolamine-Induced Amnesia in Male Swiss Mice
}

\author{
HERVÉ HERVÉ NGATANKO ABAISSOU ${ }^{1}$, FOYET HARQUIN SIMPLICE ${ }^{1 *}$, EGLANTINE KEUGONG WADO ${ }^{1}$, \\ BALBINE KAMLEU NKWINGWA ${ }^{1}$, JORELLE LINDA DAMO KAMDA ${ }^{1}$, \\ LEA BLONDELLE KENKO DJOMESSIE ${ }^{1}$, VLADIMIR POROCH ${ }^{2}$, IRINA DOBRIN ${ }^{2}$, ELISABETH NGO BUM ${ }^{1,3}$, \\ PETRU ROMEO DOBRIN ${ }^{2 *}$, ALEXANDRA BOLOS ${ }^{2 *}$, ANA-CATERINA CRISTOFOR ${ }^{2}$ \\ ${ }^{1}$ Laboratory of Cognitive and Behavioral Neuroscience, Department of Biological Science, Faculty of Science, University of \\ Maroua, Cameroon, P.O. Box: 814, Maroua, Cameroon \\ ${ }^{2}$ Grigore T. Popa University of Medicine and Pharmacy, Faculty of Medicine, 16 Universitatii Str., 700115, Iasi, Romania \\ ${ }^{3}$ Laboratory of Medicinal Plants, Health and Galenic Formulations, Department of Biological Science, Faculty of Science, \\ University of Ngaoundéré, P.O. Box 454, Ngaoundéré, Cameroon
}

The present study was conducted to investigate protective effects of the aqueous extract of $V$. subterranea seeds landrace on amnesia induced by scopolamine in mice. V. subterranea aqueous extract (100, 200 and $400 \mathrm{mg} / \mathrm{kg} \mathrm{BW}$ ) was administered by gavage for nine consecutive days and memory impairment was induced by repeated intraperitoneal injection of scopolamine $(1.5 \mathrm{mg} / \mathrm{kg})$. The $Y$-maze (YM), Morris water maze (MWM), novel object recognition paradigm (NOR) and the T maze (TM) were used to assess learning, memory and retention. Superoxide dismutase (SOD), Catalase (CAT), Malondialdehyde (MDA) levels and Acetylcholine esterase activity was also evaluated in the mice hippocampi homogenates. $V$. subterranea aqueous extract $(400 \mathrm{mg} / \mathrm{kg})$ significantly increased the percentage of spontaneous alternation in the YM task and decreased escape latency in the MWM. Moreover, this dose brought about a significantly improvement in the time spent in the preferred TM arm and discrimination index in the NOR tasks despite repeated scopolamine injection. Additionally, low acetylcholine esterase levels, reduced lipid peroxidation (malondialdehyde) but increased antioxidant enzymes (catalase and superoxide dismutase) activity was observed in hippocampi homogenate of mice pre-treated with the extract. A protective action against hippocampal cell damage was also evident. This finding suggests that the aqueous extract of V. subterranea seed landrace may improve learning and memory.

Keywords: Vigna subterranea, Alzheimer's disease, Memory impairment, Scopolamine, Antioxidant, Acetylcholine esterase.

The world's population is ageing, older persons are increasing in number and make up a growing share of the population in virtually every country [1]. Dementia prevalence is also increasing among the elderly [2]. Alzheimer's disease (AD) is a progressive neurodegenerative age-related disorder. It is the most common form of dementia characterized by a loss of hippocampal and cortical neurons leading to deterioration of cognitive abilities, memory loss and reduced learning [3-4]. Stress, genetic predisposition and some medical conditions are other risk factors related to AD development [5]. Epidemiological data from Alzheimer's disease revealed 46.8 million people with AD among the world's population in 2016. The number of AD incidence is expected to triple over the next 40 years [6]. These projected increases also have considerable emotional and financial burdens which are estimated to cost about 175.000 dollars per person with AD over their entire life [7]. Alzheimer's related dementia is also a major health concern in the elderly in Africa due to extended lifespan and growing populations [8-9].

Two main pathological hallmarks of AD are described to date. Extracellular neuritic amyloid plaques, as amyloid $\beta$ peptides deposits due to failure of the enzyme $\beta$ secretase in cleaving the amyloid precursor protein and intracellular neurofibrillary tangles which set up as a result of hyperphosphorylation of tau protein [10]. Other pathophysiological events consistent with the induction and progression of AD pathology include inflammation, cholinergic system dysfunction and oxidative stress [11].

*email: fharquins@gmail.com; petru.dobrin@umfiasi.ro; alexandra.bolos@umfiasi.ro 
The cholinergic system has been the main target in the development of drugs against AD pathogenesis as low concentration of $\mathrm{ACh}$ is seen in aging and $\mathrm{AD}$, associated with cholinergic deficit [12]. Acetylcholine esterase (AChE) enzyme catalyses the breakdown of acetylcholine thereby affecting its bioavailability in the synaptic cleft. Moreover, by binding to amyloid- $\beta$-associated proteins, $\mathrm{AChE}$ increases the rate of fibrillation and acts as a potent amyloid-promoting factor [13]. In the past years, cholinergic revival therapy through Acetyl choline esterase inhibitors (AChEI) have been employed in AD therapy [14]. But their use is associated with severe side effects, short-life span, limited bioavailability and efficacy [15]. Medicinal plants provide a rich source of biologically active constituents endowed with a wide range of activities. In the quest for more effective and innovative treatment strategies for subsequent development of innovative therapeutic compounds, herbal medicine is highly solicited. Vigna subterranea (L.) Verdc. is commonly known as "Bambara groundnut". It is a legume seed that is easily cultivated and classified under the Fabaceae family, Faboidea subfamily and Vigna genus [16].

In the Far-North Region of Cameroon, traditional healers systematically use Bambara groundnut in the treatment of persons with mental disorders ("madness"), indicating that the plant may possess interesting neuropharmacological properties. $V$. subterranea has been reported to possess high quantities of antioxidants and vitamins which could impart many health benefits and thereby reducing the risk of many chronic illnesses like cancer [17-18]. Andzouana et al. [19] reported the presence of flavonoids, phenols, alkaloids and other nutrients in Bambara groundnut. Moreover, previous studies revealed that $V$. subterranea has antiepileptic properties [20]. Cognitive disorders in epilepsy are now well established. The loss of neuronal cells of the hippocampus due to precipitating aggression (status epilepticus) and recurrent epileptic seizures lead to memory impairment [21]. Beside recurrent seizures in epileptic patients, chronic and persistent dysfunctions of limbic circuits, characteristics of epilepsy, also lead to cognitive decline [22-24]. Screening of $V$. subterranea achieved by Harris et al. [25] indicated that black and brown landraces were the richest in flavonoids, with kaemferol, being the major representative in whole seeds. Flavonoids are able to cross the blood-brain barrier, hindering neuronal damage. In a recent study, using STZ-induced AD animal model, Darbandi et al. [26] reported that, kaempferol increases the expression or activity of antioxidant enzymes and decreases the number of dead cells, especially pyramidal neurons in CA1 hippocampus area.

On the other hand, many species of the "Vigna" genus have been proven to possess potential neurological actions. Vigna radiata possess memory improvement activity, Vigna mungo has nootropic activity while Vigna unguiculata is endowed with motor coordination activity and antidepressant potentials [27-30]. Despite the promising medicinal profile, there isn't known experimental study on the protective effect $V$. subterranea extract against memory deficit in mice to date. In this context, it appeared reasonable for us to explore the effect of this plant extract on an animal model of neurodegenerative disease. Therefore, the aim of the present study was to evaluate the protective effects of the aqueous extract of $V$. subterranea on scopolamine-induced memory impairment in Swiss mice. Furthermore, we investigated the underlying mechanism by which it could induce its potential neuroprotective effects.

\section{Experimental part}

Animals

Male Swiss mice aged 4 months (20-25 g BW) were used in this study. Mice were purchased from the animal breeding facility of 'LANAVET' ("Laboratoire National Vetrinaire", Garoua, Cameroon), acclimatized for 14 days under natural dark-light cycle and provided with water and food ad libitum. The present study was approved by the Ethic Committee of the Faculty of Sciences of the University of Maroua (Ref. N¹4/0261/ Uma/D/FS/VD-RC), Cameroon. All experiments were accomplished in accordance with the guidelines of Cameroonian bioethics committee (reg $\mathrm{N}^{\circ}$.FWA-IRB00001954) and NIH- Care and Use of Laboratory Animals manual ( $8^{\text {th }}$ Edition). Efforts were also made to minimize animal suffering.

\section{Botanical materia}

\section{Collection and identification}

Dry Vigna subterranea (L.) Verdc. (Fabaceae) seeds (Fig. 1) were purchased post-harvest in the month of September 2017 from a local market (Doulek; Far North Region, Cameroon). The botanical identification of seeds and authentication was done at the National Herbarium Yaounde Cameroon by comparing to Gerling G N ${ }^{\circ} 5121$ of the collection of Herbarium No36574. 


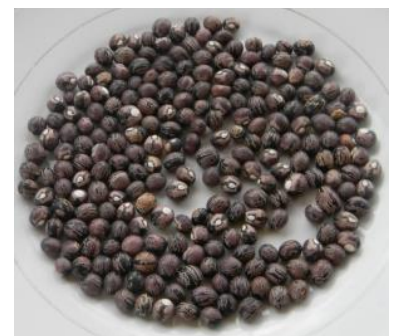

Fig. 1. Dry seeds of Vigna subterranea landrace

\section{Preparation of aqueous extract of Vigna subterranea}

The extraction was done as to match the traditional healer's method. The selected landrace was graded according to size and weighed. $250 \mathrm{~g}$ was soaked in water for 8 hours, then boiled for $1 \mathrm{~h}$ at $100^{\circ} \mathrm{C}$. The cooked seeds were crushed using a blender. The paste obtained from crushing was sintered using a $500 \mu \mathrm{m}$ mesh sift, filtered using whatman filter paper $\mathrm{N}^{\circ} 4$ and the solvent eliminated from the filtrate using a temperature controlled oven $\left(50^{\circ} \mathrm{C}\right.$ for $\left.24 \mathrm{~h}\right)$. The powder obtained was weighed and the yield of extraction determined.

\section{Drugs and chemicals}

Piracetam was obtained from UCB Pharma SA, Braine 1'Alleud (Belgium), scopolamine hydrobromide, trichloroacetic acid and thiobarbituric acid were purchased from Sigma chemical, St. Louis, MO (United States). Acetylthiocholine iodide and 5, 50-dithiobis (2-nitrobenzoic acid) (Ellman reagent), TWEEN 80, ethanol, phosphoric acid, sodium hydroxide, hydrogen peroxide, anhydrous sodium, sodium bicarbonate, dichromate acetic acid, sodium citrate, formalin and sodium pentobarbital were purchased from Biochemica (Shanghai, China).

\section{Design}

Mice were randomly divided into two sets of six groups $(n=10)$ and subjected to the following treatment schedule: Normal control group (deionized water $10 \mathrm{~mL} / \mathrm{kg}$ p.o) only; Negative control group receiving Scopolamine (1.5 mg/kg i.p.)

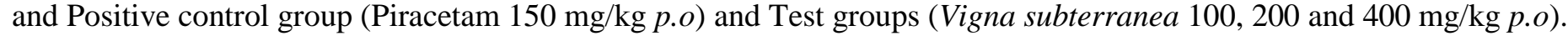

All groups were treated for 9 days. Scopolamine was dissolve in normal saline $0.9 \%$ and administered to all groups except the normal control 45 min after treatment. Behavioral tests were launched $30 \mathrm{~min}$ after Scopolamine injection.

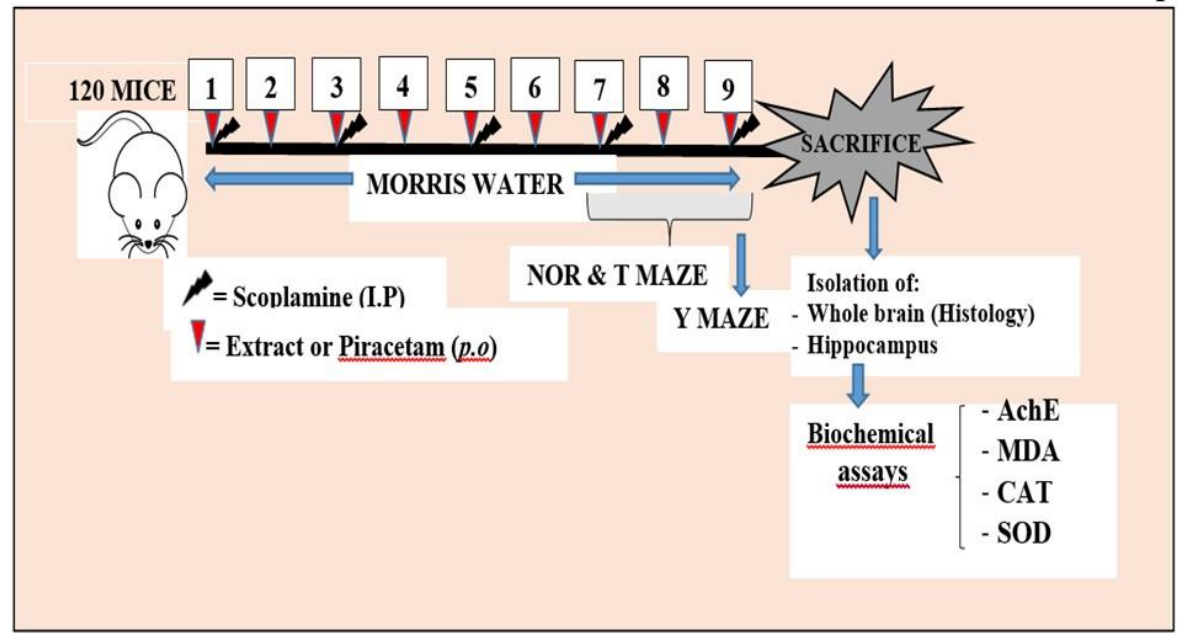

Fig. 2. Experimental schedule

\section{Behavioral studies}

All behavioral activities of mice were video tracked and recorded using ANYMAZE trial version 6.03 (USA, Wood Dale).

\section{Short-term memory and locomotor activity evaluation in the $Y$-maze test}

The Y-maze test was used to assess short term memory in mice by assessing the percentage of spontaneous alternation in a single trial $(8 \mathrm{~min})$, on the last day of the experiment. 1 hour after treatment and thirty min after scopolamine injection (except for the normal control group), behavioural parameters were recorded during the last five min of the test. The total number of arm entries was used as a measure of general activity of the animals. Specific arm transition sequences (ABC, 
$\mathrm{BCA}$, or $\mathrm{CAB}$ but not $\mathrm{BAB}$ or $\mathrm{CAC}$ or $\mathrm{CBC}$ ) were recorded as spontaneous alternation which reflects short-term memory. The maze was wiped clean with $70 \%$ ethanol between each animal to minimize odour cues [31].

\section{Novel Object recognition test}

This test was performed as earlier described by El-Marasy et al. [32] and was used to evaluate recognition in mice. Exploration was defined as follows: directing the nose toward the object at a distance of not more than $2 \mathrm{~cm}$ and/or touching the object with the nose. The arena and objects were thoroughly cleaned with $70 \%$ ethanol in order to eliminate residual odours. From this measure, a series of variables was then calculated: the total time spent in exploring the two identical objects in the first trial and that spent in exploring the two different objects, $\mathrm{F}$ and $\mathrm{N}$ in the second trial $24 \mathrm{~h}$ after the first. The discrimination index was also determined using the formula: $\mathrm{DI}=(\mathrm{N}-\mathrm{F}) /(\mathrm{N}+\mathrm{F})$.

\section{Spatial cognition and retention evaluation in the T-maze task}

This task was used to evaluate spatial memory and retention as previously described by Amico et al. [33] with slight modifications. The test was performed in three phases: habituation, acquisition and retention. In each phase, each mouse was evaluated for $5 \mathrm{~min}$ and the time spent in arms and number of return to the start arm were recorded. The floor of the apparatus was cleaned with $70 \%$ ethanol between trials to eliminate olfactory cues.

\section{Spatial learning and memory assessment in the Morris water maze}

Hippocampal-dependent spatial learning and memory was assessed using a standard Morris Water Maze (MWM) task as described previously by Harris et al. [34]. Escape latency (in sec) and distance travelled before finding the platform (in meters) was acquired by a video tracking software. Memory retention was assessed in the probe phase of the MWM which occurred 24 and $48 \mathrm{~h}$ after the fifth and final hidden platform trial. During the probe phase the platform was removed from the tank and time the mice spent in each quadrant was recorded. The percentage of time spent in the target quadrant, which previously held the hidden platform, was calculated.

\section{Biochemical assay}

At the end of the experiment (day 9), mice euthanasia involved the administration of an overdose of sodium pentobarbital $(100 \mathrm{mg} / \mathrm{kg}$ b.w., i.p., Sigma). When complete loss of righting reflex and reduction of respiratory rate was achieved, their brains were carefully excised from the skull and dissected for the isolation of hippocampi. Hippocampi were weighed and rinsed in the ice-cold isotonic saline solution. Hippocampi tissue samples were then homogenized (1:10) using a mortar and a pestle in ice-cold $0.1 \mathrm{M}$ potassium phosphate buffer ( $\mathrm{pH} 7.4)$. The homogenate was centrifuged (3000 rpm, $15 \mathrm{~min})$ and the supernatant was used for biochemical analysis.

\section{Estimation of hippocampal acetylcholine esterase enzyme activity}

Acetylcholine esterase (AChE) enzyme activity was estimated by Ellman method [35]. The change in absorbance per minute was determined at $412 \mathrm{~nm}$. The enzyme activity was calculated and expressed as AChE nmol/g of tissue/min [36].

\section{Estimation of hippocampal oxidative stress biomarkers. Estimation of Superoxide dismutase}

The Superoxide dismutase (SOD) activity in supernatant was measured by the method of Misra and Fridovich [37]. The change in absorbance of each sample was then recorded at $480 \mathrm{~nm}$ in a spectrophotometer at $20 \mathrm{sec}$ and $80 \mathrm{sec}$. One unit of SOD was defined as the amount of enzyme required to produce $50 \%$ inhibition of epinephrine auto oxidation. The specific activity of SOD was expressed in terms of SOD unit/g of organ.

\section{Estimation of Catalase activity}

Catalase (CAT) activity was assayed following the method of Sinha [38]. Absorbance was read at $570 \mathrm{~nm}$ on a spectrophotometer. The difference in absorbance per unit was used as the measure of catalase activity.

\section{Estimation of lipid peroxidation}

The level of Lipid peroxides was estimated by thiobarbituric acid reaction method described by Wilbur et al. [39]. Absorbance was determined at $532 \mathrm{~nm}$ using a spectrophotometer (Uviline 6600, Alès, France). A calibration curve was constructed using MDA as standard and the results were expressed as nmol/g protein.

\section{Histopathological Studies}

Following trans cardiac perfusion, mice were decapitated and their brains collected, fixed in $10 \%$. Fifty (50) mm coronal sections of brains in the hippocampus region were made using the mouse brain Atlas with the following coordinate 
(Anterior/Posterior D $2.0 \mathrm{~mm}$, Medial/lateral D $1.5 \mathrm{~mm}$ and dorsal/ventral AP D $2.0 \mathrm{~mm}$ ) [40]. The hippocampi sections were dehydrated, embedding in paraffin, deparaffinised, rehydrated and stained using haematoxylin and eosin stains. The brain sections were thereafter photographed and images were captured using a digital camera attached to a light microscope (Scientico, Haryana - India).

\section{Statistical analysis}

Statistical analysis was done using the software Graphpad Prism 5.0 for windows. The differences amongst groups were analyzed using One-way and Two-ways Analysis of Variance (ANOVA). P-values less than 0.05 were considered significant. Bonferroni post-test were used for multiple comparisons. Pearson's correlation coefficient and regression analysis were used to investigate the association between behavioural and biochemical parameters.

\section{Results and discussions}

Effect of $V$. subterranea on spontaneous alternation and locomotion of scopolamine demented mice in the $Y$-maze test

The impulsive memory functioning and probing behaviour of mice was investigated by recording the spontaneous alternation using the $\mathrm{Y}$ maze test. The result of spontaneous alternation shows that there are differences in the percentages of spontaneous alternation between all the groups (Fig. 3A). Scopolamine administration decreased this percentage. Pretreatment of mice with the extract at the dose of $400 \mathrm{mg} / \mathrm{kg}$, significantly $(p<0.001)$ reversed scopolamine-induced decrease in percentage of spontaneous alternation. Repeated administration of the reference drug Piracetam $(150 \mathrm{mg} / \mathrm{kg})$ also significantly increased spontaneous alternation percentage. The different doses of $V$. subterranea aqueous extract did not enhance or impair locomotor activity of scopolamine demented mice expressed as the number of entries in YM arms (Fig. $3 B)$. In this figure: each column represents mean \pm SEM of the spontaneous alternation percentage (A) and the numbers of arm entries (B) of ten mice, $\$ p<0.05, \$ \$ p<0.001$, $\$ \$ \$ p<0.0001$ vs. scopolamine treated group (DI + Scop); $\mu p<0.001$ vs. deionized water group. DI, deionized water; vs, Vigna subterranea; Scop, scopolamine; Pir, Piracetam.

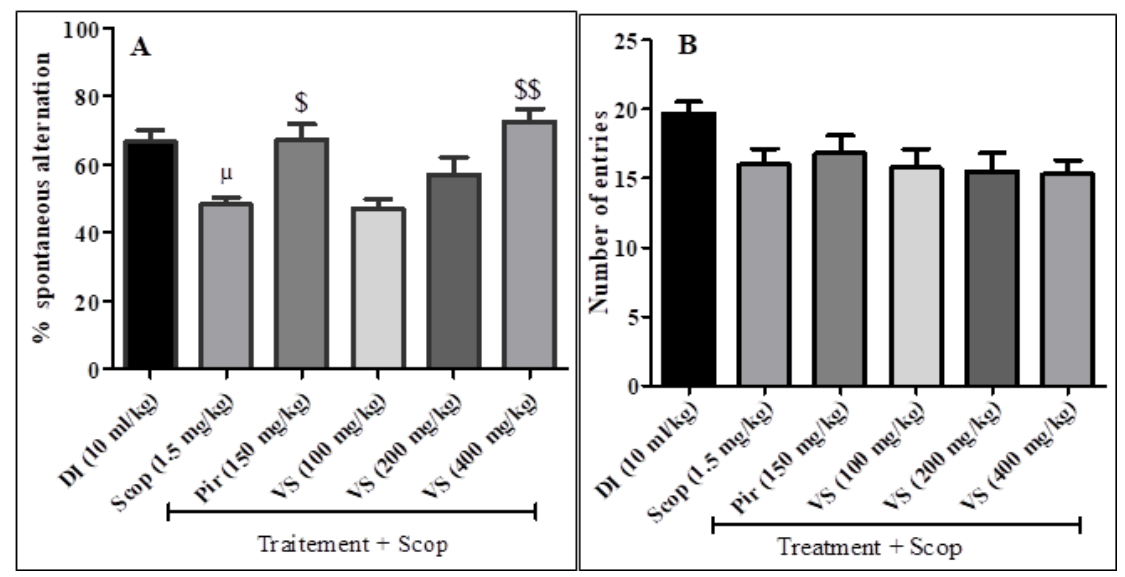

Fig. 3. Effect of Vigna subterranea on scopolamine-induced memory impairments in the Y-maze test

Effect of $V$. subterranea on recognition memory of scopolamine-induced cognitive deficit in mice

All mice that received repeated administration of different doses of $V$. subterranea as well as Piracetam spent more time exploring the novel object as compared to the familiar object (Fig. 4A). However, this was not the case with mice that received scopolamine injections only, as they spent more time exploring the novel object instead. The highest dose of the extract $(400 \mathrm{mg} / \mathrm{kg})$ brought the least significant $(p<0.05)$ increase in novel object exploration time as compared to the scopolamine treated mice. Discrimination index was significantly $(p<0.001)$ diminished in scopolamine demented rats that received the vehicle as compared to normal mice. Repeated treatment of mice with $V$. subterranea at all doses as well as Piracetam induced an increase in discrimination index. A significant $(p<0.0001)$ increased in discrimination was achieved with the lowest dose of the extract $(100 \mathrm{mg} / \mathrm{kg})$ just like the standard drug Piracetam, between the two objects (Fig. 4B). In this figure: each column represents mean \pm SEM of ten animals, $\$ p<0.05, \$ \$ p<0.001, p<0.0001$ vs. scopolamine treated group (DI + Scop); $\mu$ p < 0.001 vs. deionized water group. DI, deionized water; VS, Vigna subterranea; Scop, scopolamine; Pir, Piracetam. 

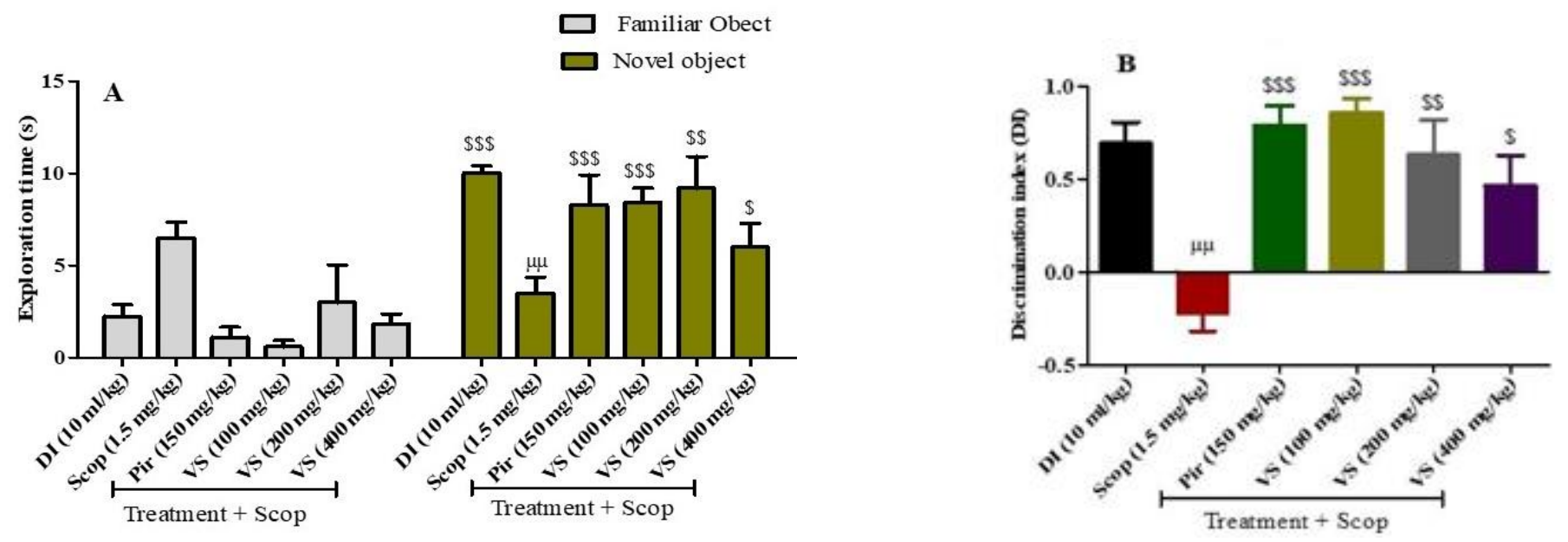

Fig. 4. Effect of Vigna subterranea on scopolamine-induced memory impairment on the exploration time of the familiar vs. novel object (A) and Discrimination Index (B) in object recognition test

\section{Effect of $V$. subterranea on retention in the T-maze task}

Repeated intraperitoneal administration of scopolamine $(1.5 \mathrm{mg} / \mathrm{kg})$ brought about a decrement in the time spent by mice in the preferred arm associated with an increment in the number of entries in the discriminated arm (Fig. 5 A, B). The standard drug (Pir $150 \mathrm{mg} / \mathrm{kg}$ ) reversed this trend with a significant $(p<0.0001)$ increase in the time spent in the preferred arm. Nine day treatment with the extract resulted in an increase in the time spent in the preferred arm. This increment was significant with the medium dose of the extract $(200 \mathrm{mg} / \mathrm{kg})$ and corresponds to about two-folds of the distilled waterscopolamine treated mice's score. All the doses of the extract reduced the number of entries in the discriminated arm. The most significant $(p<0.0001)$ decrement was obtained with the highest dose of the extract.

Related to the variable 'return into initial arm', all the doses of the aqueous extract of $V$. subterranea, significantly $(p<$ 0.0001) decreased the number of initial T-maze arm return. This performance was quite similar to that of the standard drug Piracetam, a known nootrop drug (Fig. 5C). In this figure: each column represents mean \pm SEM of ten mice, $\$ p<0.05, \$ \$$ $\mathrm{p}<0.001, \$ \$ \$ p<0.0001$ vs. scopolamine treated group (DI + Scop) $\mu \mathrm{p}<0.001$ vs. deionized water group. DI, deionized water; VS, Vigna subterranea; Scop, scopolamine; Pir, Piracetam.
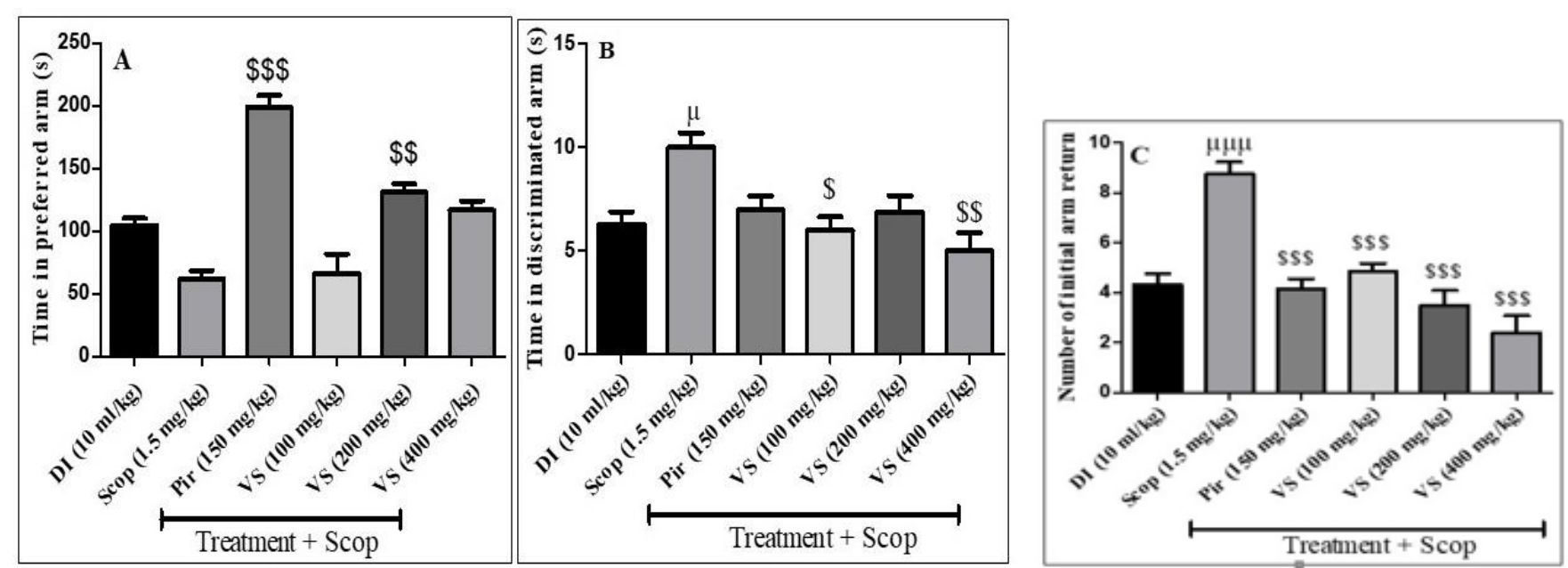

Fig. 5. Effect of Vigna subterranea on scopolamine-induced memory impairments in the T-maze test.

The time spent in the preferred arm (A), discriminated arm entries (B) and initial arm return (C)

\section{Effect of V. subterranea on visuo-spatial learning and memory in the Morris water maze}

The time taken to find the hidden platform by scopolamine-demented mice decreased throughout the acquisition and the reversal phases with the administration of all doses of the extract as compared to those that received scopolamine solely (Fig. 6A). A significant decrease $(p<0.0001)$ in escape latency was noted with the highest dose of the extract $(400 \mathrm{mg} / \mathrm{kg})$ on both the last day of acquisition and reversal training (days 3 and 6 respectively). Further, the extract and the standard drug reversed the decrease in speed related to repeated scopolamine injection. Mice that were treated with $400 \mathrm{mg} / \mathrm{kg}$ of extract had a significantly $(p<0.0001)$ increased swim speed in the pool. $24 \mathrm{~h}$ after the reversal trial, the platform was 
removed from the maze during the probe trail. Scopolamine administration significantly $(p<0.0001)$ shortened the time spent by mice in the quadrant that contained the escape platform the previous day (Fig. 6B) as compared to the control. However, Piracetam treated mice, as well as those treated with the different doses of the aqueous extract of $V$. subterranea spent more time searching the platform in the target quadrant during the probe trial. This increment in time was significant $(p<0.0001)$.

The visible platform (cued version) task, ran on the last day of the test revealed a significant $(p<0.0001)$ increase in the escape latency with the distilled water-scopolamine treated mice as compared to the normal control mice. Mice that received the different doses of the extract took less time to escape from the water. The reference drug Piracetam, significantly ( $p<$ 0.0001) shortened the escape latency as did the extract at the dose of $200 \mathrm{mg} / \mathrm{kg}$ during this phase (Fig. 6C). In this figure: each column represents mean \pm SEM of ten animals, $\$ p<0.05, \$ \$ p<0.001, \$ \$ \$ p<0.0001 v s$. scopolamine treated group (DI + Scop); $\mu$ p $<0.001$ vs. deionized water group. DI, deionized water; VS, Vigna subterranea; Scop, scopolamine; Pir, Piracetam.

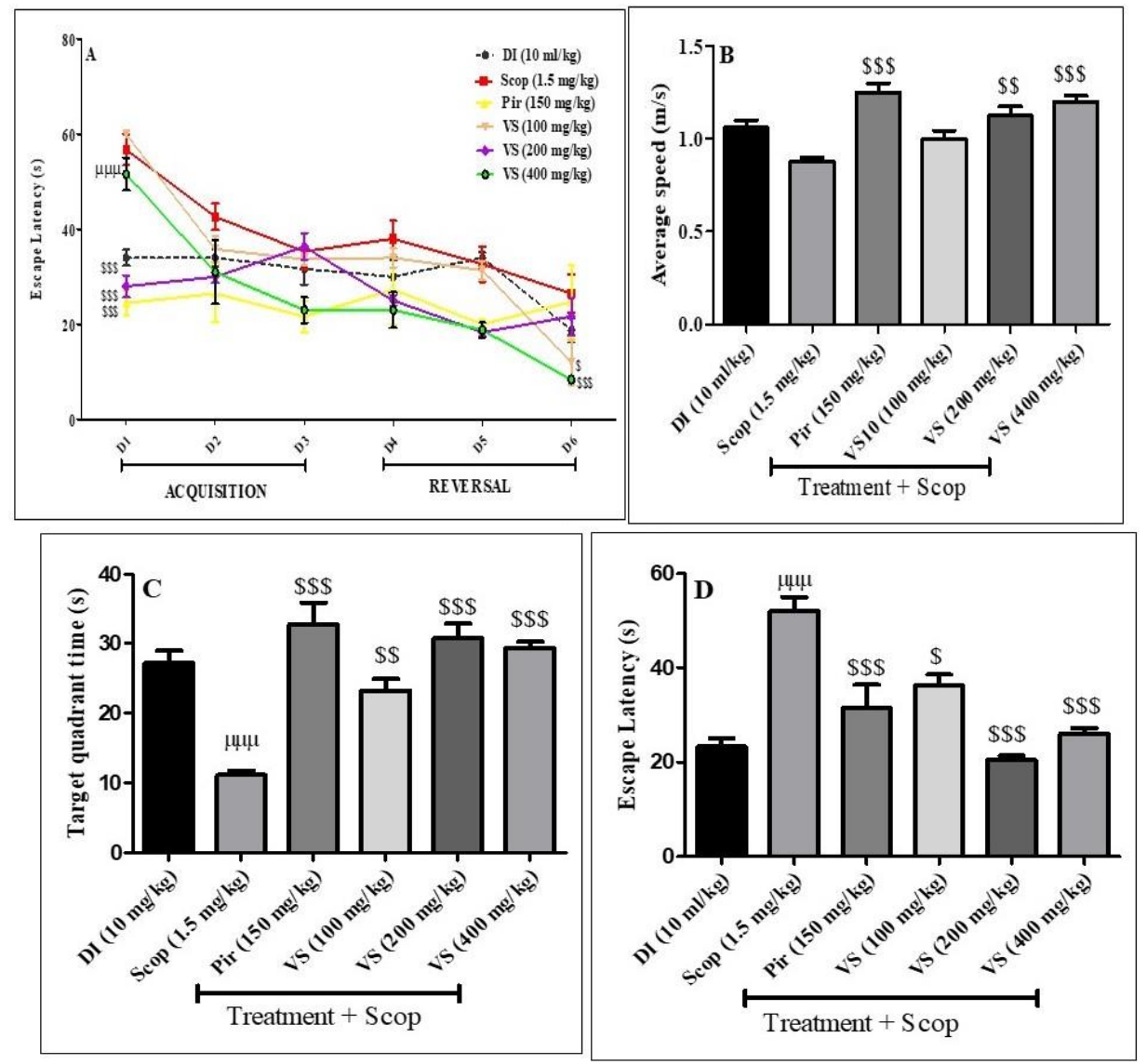

Fig. 6. Effect of Vigna subterranea on scopolamine-induced memory impairment on retention parameters in the Morris water maze. Escape latency existing platform (A), average swim speed (B), time spent in the target quadrant during probe trial inexistent platform $(\mathrm{C})$ and visible platform escape latency (D)

Effect of $V$. subterranea on cholinergic impairment, lipid peroxidation and oxidative stress. Acetylcholine esterase (AChE) activity in the hippocampus

AChE is a pivotal neurotransmitter in the cholinergic system whose main role is to breakdown acetylcholine (Ach). Scopolamine-administered mice significantly $(p<0.0001)$ increased the concentration of AChE in hippocampi as compared to the control group (Fig. 7). V. subterranea treated mice showed a decrease in hippocampal AChE activity as compared to the scopolamine-treated group. The lowest dose of the extract of $V$. subterranea $(100 \mathrm{mg} / \mathrm{kg}$ ) showed a significantly ( $p<$ 0.0001) higher suppression of AChE activity which is in line with that of the Piracetam treated group. In this figure: each column represents mean \pm SEM of ten animals, $\$ p<0.05, \$ \$ p<0.001, \$ \$ \$ p<0.0001$ vs. scopolamine treated group (DI + Scop); $\mu \mathrm{p}<0.001$ vs. deionized water group. DI, deionized water; VS, Vigna subterranea; Scop, scopolamine; Pir, Piracetam. 


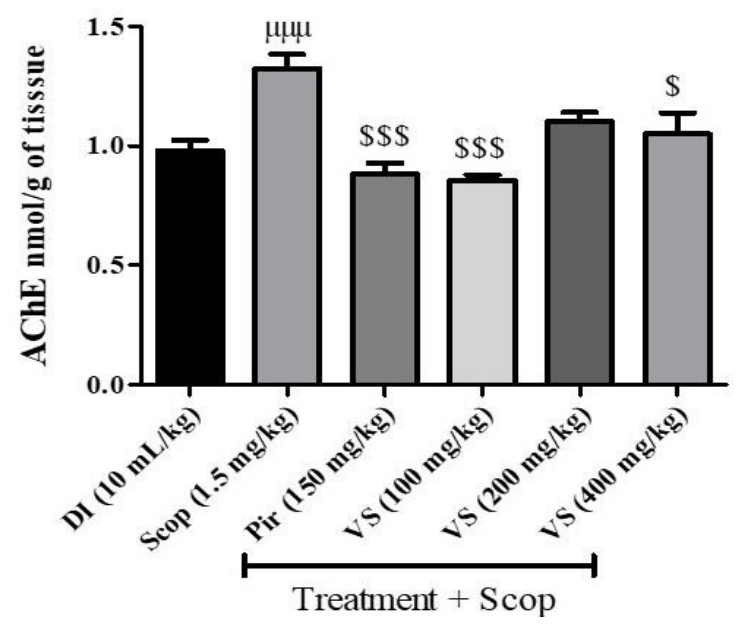

Fig. 7. Effects of Vigna subterranea on acetylcholinesterase activity of scopolamine treated mice

\section{Lipid peroxidation and oxidative stress in the hippocampus}

There is a close connection between scopolamine induced amnesia and the development of oxidative stress in brain tissues. Figure 8A shows that lipid peroxidation was significantly $(p<0.0001)$ higher in scopolamine-administered mice as compared to the control group. This level was significantly $(p<0.001)$ decreased in scopolamine-administered mice that received the standard drug Piracetam. The aqueous extract at all doses exhibited a more significant $(p<0.0001)$ reduction of lipid peroxidation in hippocampal tissue despite repeated scopolamine administration. Figures $8 \mathrm{~B}$ and $\mathrm{C}$ show that repeated administration of scopolamine decreased antioxidant enzymes (CAT and SOD) activity. However, pre-treatment with different doses of extract inhibited scopolamine-induced oxidative stress by increasing CAT and SOD activities. However statistical significance was not achieved. These increase in antioxidant enzyme activity were similar to that obtained by Piracetam, the standard drug. On the other hand, linear regressions determined revealed significant negative correlation between MDA vs. time spent in the target quadrant $(\mathrm{r}=0.704, p<0.0001)$ (Fig. 9A) and significant negative correlation between discrimination index vs. AChE activity $(\mathrm{r}=0.590, p<0.0006)$ (Fig. 9B). In figure 8: each column represents mean \pm SEM of ten animals, $\$ p<0.05, \$ \$ p<0.001, \$ \$ \$ p<0.0001$ vs. scopolamine treated group (DI + Scop); $\mu \mathrm{p}<0.001$ vs. deionized water group. DI, deionized water; VS, Vigna subterranea; Scop, scopolamine; Pir, Piracetam.
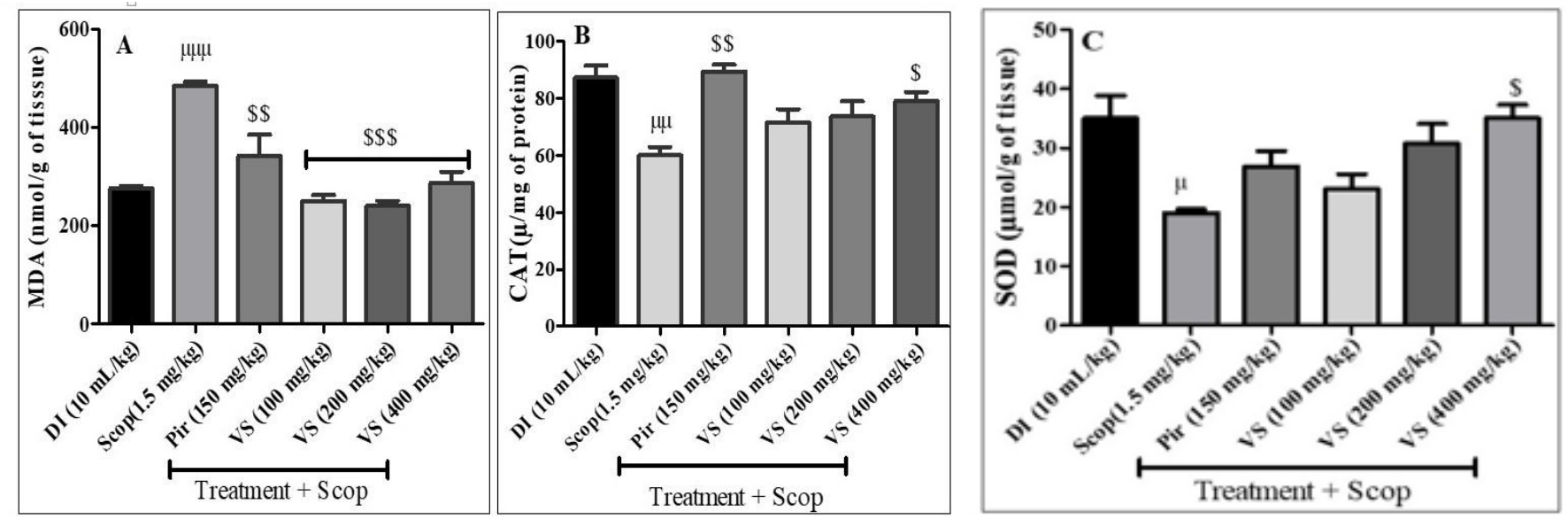

Fig. 8. Effects of Vigna subterranea on malondialdehyde level (A), catalase (B) and superoxide dismutase (C) activities in hippocampi tissue of scopolamine treated mice 


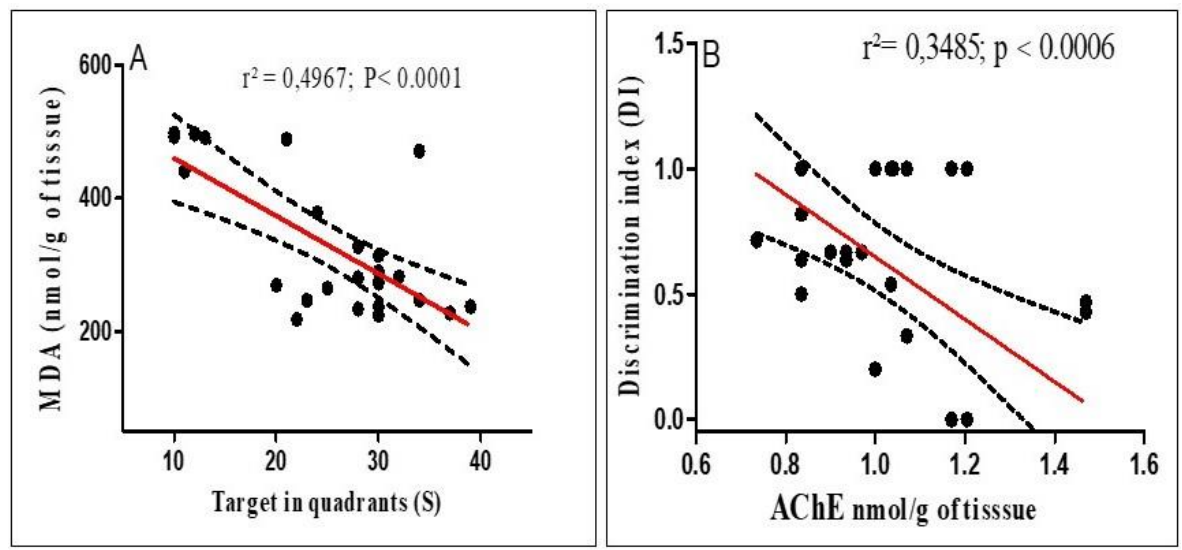

Fig. 9. Pearson's correlation between MAD vs Time spent in target quadrants (A), Discrimination index vs AChE (B)

\section{Effect of $V$. subterranea on hippocampi cell architecture}

Haematoxylin and eosine staining were used to assess hippocampi cells alteration. Repeated scopolamine injection, resulted in disorganization, decrease in thickness and regression of the density of pyramidal cells in the CA1 and CA3 sub regions and granular cells of the DG hippocampal sub regions (Fig. 10B). On the other hand, 200 and $400 \mathrm{mg} / \mathrm{kg}$ doses of the aqueous extract of $V$. subterranea reversed scopolamine induced alteration and maintained a normal architecture (Fig. $10 \mathrm{E}$ and 10F) of these regions evidenced by intact pyramidal cell thickness which is comparable to what is seen in the section of hippocampi of mice treated with the standard drug Piracetam (Fig. 10C). In this figure: Deionized water (A), Scopolamine (B), Piracetam (C), Vigna subterranea $100 \mathrm{mg} / \mathrm{kg}$ (D), $200 \mathrm{mg} / \mathrm{kg}$ (E) and $400 \mathrm{mg} / \mathrm{kg}(\mathrm{F})$. CA= Cornu Ammonis, $\mathrm{DG}=$ dentate gyrus, $\mathrm{PL}=$ pyramidal layer; representative photomicrographs were taken at magnification $400 \times$ after haematoxylin and eosin staining.
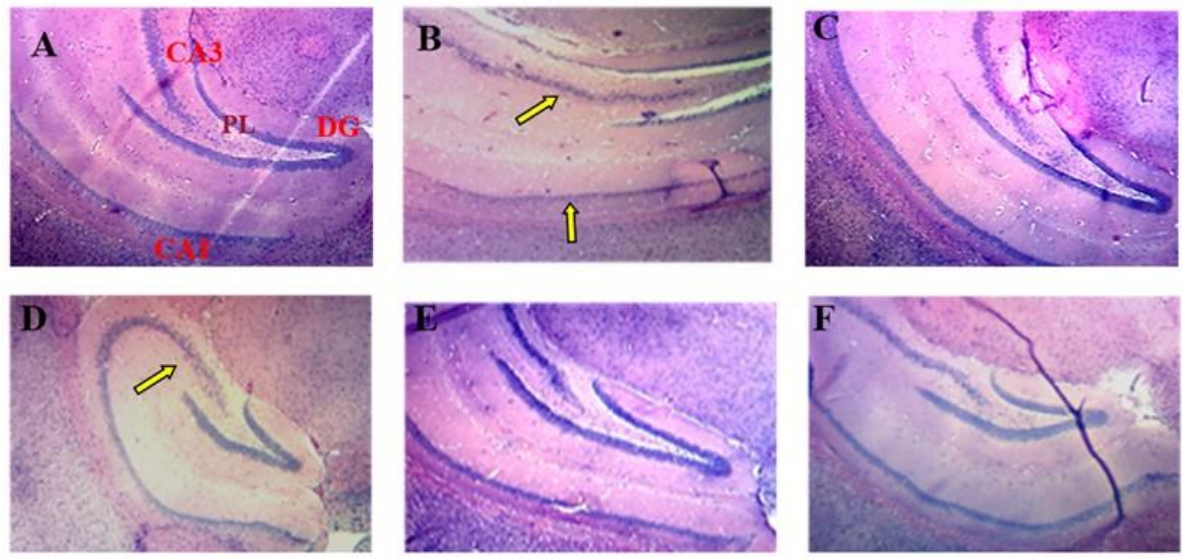

Fig. 10. Effect of Vigna subterranea on scopolamine induced neuronal cell loss in the CA1 and CA3 hippocampal sub regions

$\mathrm{AD}$ is a multifactorial neurodegenerative disorder that appears in aging adults, inflicting serious behavioral and cognitive damages. Some clinical symptoms of AD include memory loss, apathy and language disorder [41]. Scopolamine is an alkaloid which impairs learning, short term and long term memory in rodents and humans. It selectively blocks muscarinic receptors (M1), hinders cholinergic transmission leading to the development of oxidative stress status [42] and subsequent neurodegeneration associated to the deposit of tau protein and $\beta$ amyloid. [43] Scopolamine also significantly decreases ACh level and increases AChE activity [44] reason why scopolamine mediated memory impairment can be used as a valid model for investigations on molecules that may reverse AD symptoms [45]. In the present study, the potentials of $V$. subterranea aqueous extract $(100,200$ and $400 \mathrm{mg} / \mathrm{kg})$ in inhibiting behavioral and cognitive impairment associated to repeated scopolamine injection was tested in the Y-maze, NOR, T-maze and MWM. Each test highlighted a specific cognitive aspect.

The YM and the MWM are believed to be excellent tools for the evaluation of hippocampal-dependent memory [46]. Spatial working memory was assessed by scoring the percentage of spontaneous alternation [47]. Nine days treatment of mice with $V$. subterranea aqueous extract resulted in an increase in the percentage of spontaneous alternation in the YM. Krishna et al. [28] reported that, an increase in spontaneous alternation corresponds to an improvement in short-term memory while a decrease corresponds to decreased working memory. The aqueous extract of $V$. subterranea thus 
contributed in recovery from scopolamine-induced spatial short term or working memory impairment. Moreover, neither scopolamine nor the different doses of the aqueous extract of $V$. subterranea affected the number of arm entries in the Ymaze, cancelling any possible psychostimulant effect. To confirm the spatial memory enhancing potential of the extract, the MWM was used. This test also evaluates spatial and related forms of learning and memories [48]. Different doses of $V$. subterranea aqueous extract decreased the escape latency in the MWM. This result evidence the efficacy of the extract in ameliorating spatial learning and memory across the acquisition and retention phases of the MWM tasks. It has been reported that, the decrement in escape latency of the first trial of each day is a representation of reference memory, while a decrease in this parameter from one trial to the next is an icon of working memory $[49,50]$. Treatment with the aqueous extract facilitated recall of the platform position in the MWM, confirming its spatial memory effect observed in the YM. Spatial navigation is very important to rodents and many other species and this depends on their ability in learning and remembering locations. Deficit in short-term episodic memory, attention and spatial orientation have been reported as early symptoms of $\mathrm{AD}[51,52]$; as spatial information gotten from sensory inputs (neocortex) are encoded by hippocampal and parahippocampal place and grid cells respectively [53]. So V. subterranea aqueous extract's spatial learning and memory ameliorating action might be related to its potential in reversing the marked scopolamine-induced cognitive decline.

Additionally, retention which is an index of long term memory was first assessed by scoring mice spatial bias for the platform location in the probe trial of the MWM. The extract increased the motivation of mice in searching the absent platform as they spent more time in the target quadrant during the probe trial. Memory retention was investigated further using the NOR test [54]. This test measures non-spatial working memory based on the natural exploratory propensity of a rodents. Scopolamine-treated mice couldn't discriminate the novel object from the familiar object. V. subterranea aqueous extract pre-treatment protected against recognition memory deficit as indicated by significantly higher discrimination index, a cue of good recognition memory. This result is consistent with the time spent in the target quadrant of the MWM, supporting the long term memory enhancing potential of the extract. To confirm the potential of $V$. subterranea aqueous extract on both scopolamine-induced retention and spatial short-term memory deficits, the T-maze test, well know sensitive tool for the detection of hippocampal dependent dysfunction was used [55]. Treatment with the aqueous extract could increase the time spent in the preferred arm associated with a decrease in the time spent in the discriminated arm and number of initial arm return. Storage and retrieval of newly acquired information are ensured by a complex circuit consisting of numerous cognitive projections extending from Meynert's nucleus basilis to the hippocampus, amygdala and through the cortex [56]. In a nutshell, the cognitive behavioral tests revealed that the aqueous extract of $V$. subterranea improves scopolamine-induced short and long term memory deficit.

Cholinergic function governs vital aspects of memory [57]. The amygdala, hippocampus and cortices are the main brain regions known to be involved in the learning and memory processes through cholinergic transmission. In the neurochemical analysis to elucidate the mechanism of memory-enhancing effect of $V$. subterranea through the cholinergic system, hippocampal acetylcholine level was measured. The hippocampus has long been known as the key structure involved in cognitive map formation [58]. Lesions, Long-term Potentiation (LTP) saturation, pharmacological inhibition, the loss-offunction of receptors within the hippocampus may affect spatial learning and memory [59-62]. Cognitive disorder has been associated with constant Ach deficiency which results from overexpression of AchE activity [63]. Hence, inhibition of $\mathrm{AChE}$ can be a potential source of treatment for AD related cognitive impairment. We found that, repeated scopolamine injection brought about a significant increase in the AChE in mice hippocampi homogenates. But treatment with $V$. subterranea aqueous extract recovered the increment in the AChE hippocampal homogenate of scopolamine treated mice. Therefore, our results suggest that the aqueous extract of $V$. subterranea has the potential to treat cognitive dysfunction in scopolamine demented mice possibly through AChE inhibition. There exist similar reports [64-65] on the potential of other plant extracts in enhancing the availability of acetylcholine within synapses. Besides AChE increment, there is evidence that reactive oxygen species generated by oxidative stress potentially plays a vital role in the development of AD amongst elderly persons [66]. Lipid peroxidation is one of the most important indicator of neurodegeneration occurrence in the brain. The major structural and components of cell membrane; lipids and proteins are vulnerable to oxidation by free radicals [67]. Unlike other membranes, neuronal membranes' key constituents are polyunsaturated fatty acids involved in signal transfer. A third of the inhaled oxygen is consumed by the brain making it a favorable site for lipid peroxidation [68]. In this study, scopolamine administration induced oxidative stress by significantly elevating MDA level, indicating lipid peroxidation. All the doses of $V$. subterranea aqueous extract significantly suppressed this increment. Lipid peroxidation may be enhanced due to decreased levels of the key antioxidant enzyme CAT and SOD [69]. $\mathrm{H}_{2} \mathrm{O}_{2}$ release is associated with the formation of other oxidant species. Catalase is endowed with the ability to detoxify $\mathrm{H}_{2} \mathrm{O}_{2}$ [70]. Similarly, SOD plays a role in detoxifying superoxide anions which damage cell membrane macromolecules. Repeated injection of scopolamine was found to decrease the level of CAT and SOD in hippocampi homogenates. Pre-treatment with $V$. subterranea aqueous extract preserved the activity of these antioxidant enzymes. The antioxidant effect of the aqueous extract of $V$. subterranea might be related to its antioxidant properties. Krishna et al. [28] findings also revealed the nootropic potential of Vigna mungo through 
antioxidant activity. Moreover, there is evidence that adult hippocampal neurogenesis is very important in memory consolidation in the brain [71]. This could be also correlated with our latest work on the oxytocin relevance in most of the neuropsychiatric disorders [72, 73]. Scopolamine injection resulted in the death of small and large pyramidal cells of the CA1 and CA3 regions and the dentate gyrus granular cells. V. subterranea aqueous extract protected the hippocampus from cell death associated to repeated scopolamine injection thereby maintaining an intact cell architecture. The observed effects of $V$. subterranea in rescuing the deficits in hippocampal neurons, may be attributed to the redox imbalance which altered hippocampal neurons, resulting in learning and memory deficits. Though compounds responsible for the $V$. subterranea aqueous extract neuroprotectory, learning and memory improving effects were not evaluated in this study, there is evidence that its seeds contain, alkaloids, saponins and many polyphenolic compounds mainly from the class of flavonoids [18-19, 74-75]. The ability of the extract to inhibit oxidative stress could thus be linked to the antioxidant nature of compounds found in the extract.

Additionally, when linear regression was determined, we found significant negative correlation between MDA vs. time spent in the target quadrant and between discrimination index vs. AChE activity. The increment in behavioral scores in the MWM and NOR tests alongside with decrease in MDA content and a decrease in AChE activity could be correlated with the involvement of the aqueous extract of $V$. subterranea in neuroprotection against lipid peroxidation AChE expression induced by scopolamine in mice hippocampi.

\section{Conclusions}

The aqueous extract of Bambara groundnut enhances hippocampal-dependent learning and memory. This effect may be attributed to its AChE inhibitory activity and antioxidant potential that were observed in this study. Hence dietary usage of Bambara groundnut could be beneficial and can also be associated to existing therapies as an adjuvant in the treatment of amnesia.

Abbreviations: AD: Alzheimer's disease; CA: Cornu Ammonis; DTNB: 5,5'-Dithiobis-(2-nitrobenzoic acid); V. subterranea: Vigna subterranea; BW: Body weight; YM: Y-maze; MWM: Morris water maze; NOR: Novel object recognition; TM: T maze; AChE: Acetylcholine esterase; MDA: Malondialdehyde; CAT: Catalase; SOD: Superoxide dismutase.

Acknowledgement: We are grateful to Prof. Dzeufiet Djomeni Paul Désiré of the Laboratory of Animal Physiology of the University of Yaoundé I for his technical assistance in the achievement of biochemical and histological studies.

\section{References}

1.UNITED NATIONS, Department of Economic Affairs, Population Division. World Population Ageing. New York: United Nations 2017 , p. 2. 2.LANGA, K.M., CRIMMINS, E., HAYWARD, M.D., Oxford Textbook of Neurological and Neuropsychiatric Epidemiology (in press). Oxford, UK: Oxford University Press, 2018.

13.KIMURA, R., OHNO, M., Neurobiol. Dis., 33, 2009, p. 229.

4.ALZHEIMER'S ASSOCIATION, Alzheimer's disease facts and Figure, Alzheimer's Dement., 12, 2016, p. 459.

5.KAPLAN, D.B., BERKMAN, B., Dementia Care: A global concern and social work challenge. International Social Work, 54, no. 3, 2011 , p. 361. 6.BARNES, D.E., YAFFE, K., Neurology, 10, 2011, p. 819.

7.CASTELLANI, R.J., ROLSTON, R.K., SMITH, M.A., Dis. Mon., 56, 2010, p. 484.

8.KALARIA, R.N., MAESTRE, G.E., ARIZAGA, R, FRIEDLAND, R.P., GALASKO, D., HALL K., et al., Lancet Neurol., 7, 2008 , p. 812.

9.OLAYINKA, O.O., MBUYI, N.N., Int. J. Alzheimers Dis., 195, 2014, p. 750.

10. ITTNER, L.M., GÖTZ, J., Nat. Rev. Neurosci., 12, no. 2, 2011, p.67.

11. ANAND, R., GILL, K.D., MAHDI, A.A., Neuropharmacol., 76, 2014, p. 27.

12. MICHEAU, J., MARIGHETTO, A., Behav. Brain. Res., 221, 2010, p. 424.

13. INESTROSA, N.C., ALVAREZ, A., PEREZ, C.A., MORENO, R.D., VICENTE, M., LINKER C., et al., Neuron, 16, no. 4, 1996, p. 881.

14. HEBERT, L.E., SCHERR, P.A., BIENIAS, J.L., BENNETT, D.A., EVANS, D.A., Arch. Neurol., 60, 2003 , p. 1119.

15.CASEY, D.A., ANTIMISIARIS, D., O'BRIEN, J., P \& T: a peer-reviewed journal for formulary management, 35, no. 4, 2010 , p. 208.

16. BAMISHAIYE, O., ADEGBOLA, J.A., BAMISHAIYE, E., Adv. Agric. Biotech., 1, 2011, p. 60.

17. MBAGWU, F.N., OKAFOR, V.U., EKEANYANWU, J., Afr. J. Plant Sci., 5, 2011, p. 370.

18. CHEN, A.Y., CHEN, Y.C., Food Chem., 138, no. 4, 2013, p. 2099.

19. ANDZOUANA, M., MOMBOULI, J.B., ATTIBAYEBA., Pak. J. Biol. Sci., 17, no. 9, 2014, p. 1083.

20. ROMEIRAS, M.M., DUARTE, M.C., INDJAI, B., CATARINO, L., Am. J. Plant Sci., 3, 2012, p. 1028.

21.RIVERA-CARVANTES, M., JARERO-BASULTO, J., FERIA-VELASCO, A., BEAS-ZARATE, C., NAVARRO-MEZA, M., GONZALEZLOPEZ, M., et al., Neuroscience, 315, 2017, p. 57.

22. CURIA, G., LUCCHI, C., INET, J., UALTIERI, F., MARINELLI, C., TORSELLO, A., et al., Curr. Med. Chem., 21,2014 , p. 663.

23. SCHMEISER, B., ZENTNER, J., PRINZ, M., BRANDT, A., FREIMAN, T., Epilepsy Res., 129, 2017, p. 51.

24.NUSSBAUM, L.A., HOGEA, L.M., FOLESCU, R., GRIGORAS, M.L., ZAMFIR, C.L., BOANCA, M., ERDELEAN, D., ROSCA, E.C.I., NUSSBAUM, L., SIMU, M.A., LUPU, V., Rev. Chim. (Bucharest), 69, no 4, 2018, p. 965.

25. HARRIS, T., JIDEANI, V., ROES-HILL, M.L., Heliyon, 4, 2018, p. 833.

26. DARBANDI, N., RAMEZANI, M., KHODAGHOLI, F., NOORI, M., BIOLOGIJA, 62, no. 3, 2016, p. 157.

27. BHANDURGE, A.P., KSHIRSAGAR, S., PRATAPWAR, A.S., Int. J. Res. Ayurveda Pharm., 3, no. 5, 2012 , p.724.

28. KRISHNA, M.C., SWETHA, P., MADHAN, M.E., Inter. J. Phytopharmacol., 5, no. 3, 2014, p. 190. 
29. ADUEMA, W., AMAH, A.K., IZUWANNE, D.I., Glob. J. Health Sci., 12, no. 2, 2016, p. 531.

30. LATEEF, A.A., THEOPHILUS, A.A., SAMUEL, S.A., JULIUS, K.O., IDOWU, J.O., ADESOJI, M.A., et al., IJNBS, 5, no. 1, 2017 , p. 7.

31.HERNÁNDEZ-CHAN, N.G., GÓNGORA-ALFARO, J.L., ÁLVAREZ-CERVERA, F.J., SOLÍS-RODRÍGUEZ, F.A., HEREDIA-LÓPEZ, F.J., ARANKOWSKY-SANDOVAL, G. Behav. Brain Res., 225, no. 2, 2011, p. 482.

32. EL-MARASY, S.A., EL-SHENAWY, S.M., EL-KHATIB, A.S., EL-SHABRAWZ, O.A., KENAWY S.A., Bull. Fac. Pharm. Cairo Univ., 50, 2011, p. 81.

33. AMICO, F., SPOWART-MANNING, L., ANWYL, R., ROWAN, M.J., Eur. J. Pharmocol., 577, 2007, p. 71.

34. HARRIS, C., VOSS, K., MURCHISON, C., RALLE, M., FRAHLER, K., CARTER, R., et al., J. Alzheimer's Dis., 41, 2007, p. 179.

35. ELLMAN, G.L., COURTNEY, K.D., ANDERS, U., FEATHER STONE, R.M., Biochem. Pharmacol., 7, 2007, p. 88.

36.SRIKUMAR B.N., RAMKUMAR K., RAJU T.R., SHANKARANARAYANA RAO, B.S. (eds.), National Institute of Mental Health and Neuro Sciences, Bangalore, India, 2004, p. 142.

37. MISRA, H.P., FRIDOVICH, I., Biochem., 15, 1967, p. 681.

38. SINHA, K., Analyze biochemistry, 47, 1972, p. 389.

39. WILBUR, K., BERNHEIN, F., SHAPIRO, O., Arch. Biochem. and Biophys., 24, 1949, p. 3959.

40. PAXINOS, G., FRANKLIN KEITH, B.J., Medical, 1, 2001, p. 264.

41. BOUBLAY, N., SCHOTT, A.M., KROLAK-SALMON, P., Eur. J. Neurol., 23, 2016, p. 1500.

42. SOODI, M., NAGHDI, N., HAJIMEHDIPOOR, H., CHOOPANI, S., SAHRAEI, E., Res. Pharm. Sci., 9, 2014, p. 107.

43. DE FELICE, F.G., WU, D., LAMBERT, M.P., FERNANDE, S.J., VELASCO, P.T., LACOR, P.N., et al., Neurobiol. Aging, 29, 2008 , p. 1334.

44. LEE, S., KIM, J., SEO, S.G., CHOI, B., HAN, J., LEE, K.W., KIM, J., Pharmacol. Res., 409, no. 85, 2014 , p. 23.

45. TABARI, S.S., BABRI, S., MIRZAIE, F., FARAJDOKHT, F., MOHADDES, G., Acta Cir. Bras., 31, 2016 , p. 520.

46. CARLA, M.Y., HONGXIN, D., JOHN, G.C., Behav. Pharmacol., 18, no. 5-6, 2007, p. 347-363.

47. GOODARZI, Z., MELE, B., GUO, S., HANSON, H., JETTE, N., PATTEN, S., et al., BMC Neurol., 16, no. 1, 2016 , p. 244.

48. VORHEES, C.V., WILLIAMS, M.T., Nat. Protoc., 1, 2006, p. 848.

49. LINDNER, M.D., HOGAN, J.B., HODGES, D.B.J., ORIE, A.F., CHEN, .P, CORSA, J.A., et al., Psychopharmacology, 188, no. 4 , 2006 , p. 629.

50. LEE, K.Y.S., SUNG, H., KIM, S.H., JANG, Y.P., OH, T.H., KIM, Y.C., Arch. Pharm. Res., 32, no. 5, 2009 , p. 677.

51. SNOWDEN, J.S., THOMPSON, J.C., STOPFORD, C.L., RICHARDSON, A.M.T., GERHARD, A., NEARY, D., et al., Brain, 134, 2011 , p. 2478.

52. CAPURRO, V., BUSQUET, P., LOPES, J.P., BERTORELLI, R., TAROZZO, G., BOLOGNESI, M.L., et al., PLoS One, 8, no. 2 , 2013 , p. 56870.

53. TOMER, I., RAVIT, M., YORAM, L., KATHLEEN, J.G., EITAN, O., Brain Behav. Immun., 61, 2016, p. 132.

54. DERE, E., HUSTON, J.P., DE SOUZA, S.M., Neurosci. Biobehav. Rev., 31, 2007, p. 673.

55. PIOLI, E.Y., GASKILL, B.N., GILMOUR, G., TRICKLEBANK, M.D., DIX, S.L., BANNERMAN, D., et al., Behav. Brain Res., 261, 2007, p. 249.

56. JOHN, D.M., MARK, B., LAWRENCE, P., CHARLES, W., MATTHEW, B., JESSICA, M. J. Psychiatr. Res., 48, 2008 , p. 526.

57. ISMAIL, O.I., TOTA, S.K., ADEYEMI, O.O., AGBAJE, E.O., SHUKLA, R., J. Pharmaceutical Bio., 51, no. 7, 2013 , p. 825.

58. O'KEEFE, J., NADEL, L., The hippocampus as a cognitive map. Walton Street, Oxford OX2 6DP 1978.

59. BRANDEIS, R., BRANDYS, Y., YEHUDA, S., Int. J. Neurosci., 48, 1989, p. 29.

60.WHITLOCK, J.R., HEYNEN, A.J., SHULER, M.G., BEAR, M.F., Science, 313, 2006, p. 1093.

61MCNAMARA, R.K., SKELTON, R.W., Brain Res. Rev., 18, 1993, p. 33.

62. SUH, J., RIVEST, A.J., NAKASHIBA, T., TOMINAGA, T., TONEGAWA, S., Science, 334, 2011, p. 1415.

63. DEAK, F., KAPOOR, N., PRODAN, C., HERSHEY, L., Neurol. Clin. Pract., 6, 2016, p. 523.

64. FOYET, H.S., NGATANKO, A.H.H., WADO, E., ACHA, A.E., ALIN, C., Complement Altern. Med., 2015 p. 333.

65. SIMAGOL, G., MALIHE, M., MAHMOUD, H., FARIMAH, B., HAMID, R.S., Drug Chem. Toxicol., 42, no. 2 , 2019 , p. 167.

66. POPRAC, P., JOMOVA, K., SIMUNKOVA, M., KOLLAR, V., RHODES, C.J., VALKO, M., Trends Pharmacol. Sci., 38, 2017, p. 92.

67. LOBO, V.A., PATIL., A., PHATAK CHANDRA, N., Pharmacogn. Rev., 383, 2010, p. 295.

68. SUlTANA, R., PERLUIGI, M., BUTTERFIELD, D.A., Bio. Med., 62, 2013, p. 157.

69. ANSARI, M.A., SCHEFF, S.W., J. Neuropathol. Exp. Neurol., 69, 2010, p. 155.

70. CELIK, V.K., ERSAN, E., ERSAN, S., BAKIR, S., DOGAN, O., Adv. Biosc. Biotech., 4, 2013, p. 183.

71. VIVAR, C., Curr. Top Med. Chem., 15, 2015, p. 2175.

72. BALMUS, I.M., LEFTER, R, CIOBICA, A., ANTIOCH, I., ABABEI, D., DOBRIN, R., Psychiatria Danubiana, 30, no.1, 2018 , p. 91.

73.PADURARIU, M., LEFTER, R., CIOBICA, A., PAULET, M., DOBRIN, R., EUROPEAN NEUROPSYCHOPHARMACOLOGY, 26, no. 2 , 2016, p. 89-90 DOI: 10.1016/S0924-977X(16)31185-3.

74. NYAU, V., PRAKASH, S., RODRIGUES, J., FARRANT, J., Am. J. Food Nutr., 3, 2015, p. 7.

75.MARANGOCI, N., TIMPU, D., CORCIOVA, A., MIRCEA, C., PETROVICI, A.R., NICOLESCU, A., URSU, E.L., NASTASA, A., URSU, E.L., NASTASA, V., BOSTANARU, A.C., MARES, M., PERTEA, M., PINTEALA, M., Pharmaceutics, 11, no. 6, 2019 , p. 295.

Manuscript received: 05.12 .2019 